\title{
All-optical demultiplexing and wavelength conversion in an electroabsorption modulator
}

Oxenløwe, Leif Katsuo; Hilliger, E.; Tersigni, Andrea; Nik, A. M.; Højfeldt, Sune; Romstad, Francis Pascal; Yvind, Kresten; Skovgaard, Peter M. W.; Hoppe, K.; Hanberg, J.

\section{Published in:}

Proceedings on The 27th European Conference on Optical Communication

Link to article, DOI:

10.1109/ECOC.2001.989127

Publication date:

2001

Document Version

Publisher's PDF, also known as Version of record

Link back to DTU Orbit

Citation (APA):

Oxenløwe, L. K., Hilliger, E., Tersigni, A., Nik, A. M., Højfeldt, S., Romstad, F. P., Yvind, K., Skovgaard, P. M. W., Hoppe, K., \& Hanberg, J. (2001). All-optical demultiplexing and wavelength conversion in an electroabsorption modulator. In Proceedings on The 27th European Conference on Optical Communication (Vol. 4, pp. 604-605) https://doi.org/10.1109/ECOC.2001.989127

\section{General rights}

Copyright and moral rights for the publications made accessible in the public portal are retained by the authors and/or other copyright owners and it is a condition of accessing publications that users recognise and abide by the legal requirements associated with these rights.

- Users may download and print one copy of any publication from the public portal for the purpose of private study or research.

- You may not further distribute the material or use it for any profit-making activity or commercial gain

- You may freely distribute the URL identifying the publication in the public portal 


\title{
All-optical Demultiplexing and Wavelength Conversion in an Electroabsorption Modulator
}

\author{
L.K. Oxenlowe(1), E. Hilliger(2), A. Tersigni(1), A.M. Nik(1), S. Højfeldt(1), F. \\ Romstad(1), K. Yvind(1), P.M.W. Skovgaard(1), K. Hoppe(3), J. Hanberg(3)
}

(1) COM, Technical University of Denmark, Building 345V, DK-2800 Kgs. Lyngby, Denmark (lo@com.dtu.dk)

(2) Heinrich Hertz Institute, Berlin

(3) GiGA-Intel, Denmark

\begin{abstract}
Cross-absorption modulation in an electroabsorption modulator is utilised to perform $80 / 10 \mathrm{~Gb} / \mathrm{s}$ alloptical demultiplexing. An improvement in receiver sensitivity at $10 \mathrm{~Gb} / \mathrm{s}$ is demonstrated when wavelength converting.
\end{abstract}

\begin{abstract}
Introduction
The electroabsorption modulator (EAM) seems set to become a key component in ultra fast OTDM systems with its many possible functionalities and its inherent simplicity. Hence, the EAM has recently been demonstrated as the central component in a $160 \mathrm{~Gb} / \mathrm{s}$ transmitter and a $160 \mathrm{~Gb} / \mathrm{s}$ receiver [1]. All-optical functionalities demonstrated include wavelength conversion and regeneration at $40 \mathrm{~Gb} / \mathrm{s}$ using cross-absorption modulation (XAM) [2], clock recovery and simultaneous demultiplexing at $20 \mathrm{~Gb} / \mathrm{s}$ using XAM [3], wavelength conversion at $40 \mathrm{~Gb} / \mathrm{s}$ using XPM [4], and $60 \mathrm{~Gb} / \mathrm{s}$ transmultiplexing using XAM [5].

In this paper we demonstrate all-optical demultiplexing of an up to $80 \mathrm{~Gb} / \mathrm{s}$ data signal down to a $10 \mathrm{~Gb} / \mathrm{s}$ channel, and further demonstrate a negative receiver penalty when wavelength converting a $10 \mathrm{~Gb} / \mathrm{s}$ signal in a multi quantum well EAM.
\end{abstract}

\section{Basic Principle - Saturable Absorption}

The principle for the demultiplexing and the wavelength conversion is cross-absorption modulation between two signals, and the experimental set-up is shown in figure 1 .

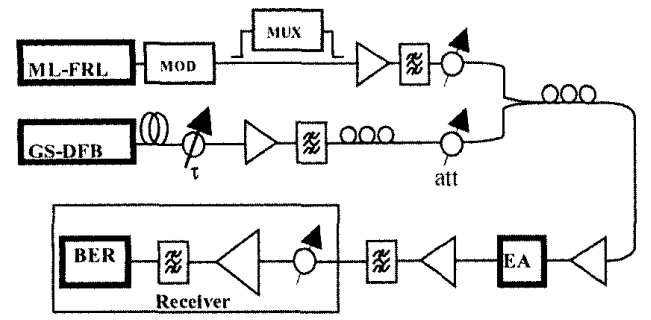

Figure 1: Schematic Set-up.

The EAM used here is a multi quantum well (MQW) InGaAsP device with 10 wells each $10 \mathrm{~nm}$ wide. By applying an external voltage to the EAM the absorption edge is shifted towards higher wavelengths through the quantum confined Stark effect (QCSE). Hence, wavelengths previously free to propagate through the EAM are absorbed [6]. Injecting a high power optical pump into the EAM can then bleach this electrically induced absorption. This absorption saturation is due to a combination of bandfilling in the quantum wells, and a reduction of the external field in the active region caused by the photogenerated carriers. In this experiment a gain- switched DFB (GS-DFB) laser with compressive fibre and a modelocked fibre ring laser (ML-FRL) are used to generate short pulses with widths of 6 ps and 2 ps respectively. The pulses are co-propagating into the EAM with a variable relative time delay, and with separate adjustable attenuators, allowing either of the two to act as the high power pump or the low power probe. The MLFRL pulses are modulated with a $10 \mathrm{~Gb} / \mathrm{s} 2^{31}-1$ PRBS sequence in a $\mathrm{LiNbO}_{3} \mathrm{MZ}$ modulator and either used at 10 $\mathrm{Gb} / \mathrm{s}$ or multiplexed up to a 40 or $80 \mathrm{~Gb} / \mathrm{s}$ data stream. In the case of wavelength conversion, the GS-DFB laser acts as probe and is absorbed in the EAM unless a high power data pulse from the ML-FRL passes through. After the EAM the converted data is filtered through a passive $\lambda$ filter, and detected in the preamplified BER receiver. In the case of demultiplexing the data pulses from the ML-FRL act as probe pulses and are absorbed in the EAM unless a GS-DFB pump pulse at $10 \mathrm{GHz}$ repetition rate saturates the absorption. After the EAM the demultiplexed ML-FRL pulses are filtered and detected in the BER receiver
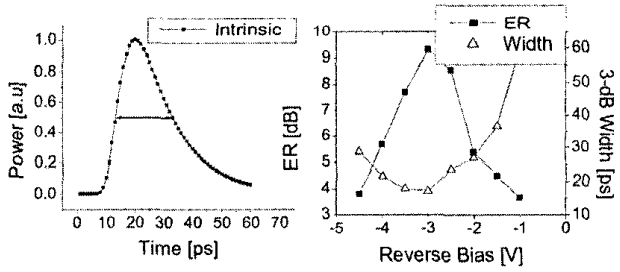

Figure 2: Left: Probed switching window (20 ps width). Right: window width and extinction ratio.

In figure 2 (left) the absorption saturation due to a $13 \mathrm{pJ}$ pump pulse (from the ML-FRL) is probed with a weaker $(0.1 \mathrm{pJ})$ GS-DFB probe pulse by changing the relative delay between the pulses [7]. The switching window shown is after deconvolution with the 6 ps probe pulse, and reveals the intrinsic switching window with a $3-\mathrm{dB}$ width of only $20 \mathrm{ps}$. Due to the carrier sweep-out time, the window becomes asymmetric though. Hence, pulses in succeeding timeslots will not be completely suppressed and therefore give rise to intersymbol interference (ISI) when demultiplexing. However, in the $40 \mathrm{~Gb} / \mathrm{s}$ case, i.e. with 25 ps separation between neighbouring channels, the transmitted power for the following channel is suppressed with $7.2 \mathrm{~dB}$, and error-free demultiplexing should therefore be possible. In figure 2 (right), the $3-\mathrm{dB}$ width of the switching windows and the extinction ratios (ER) for 
different bias values are shown. The narrowest window with highest ER is found around $-3 \mathrm{~V}$, and is 16 ps wide and $9.3 \mathrm{~dB}$ high. However, the overall shape of the window is influenced by the bias, so the optimum bias point, where neighbouring channels are suppressed the most, depend slightly on the bit-rate.

\section{Wavelength Conversion}

Wavelength conversion is performed with both a CW probe and a pulsed probe. The ML-FRL acts as a data-modulated pump at $10 \mathrm{~Gb} / \mathrm{s}$ with about $13 \mathrm{pJ}$ pulse energy $(18 \mathrm{dBm}$ average power) at $1548 \mathrm{~nm}$. The probe from the DFB laser is fixed at $1553 \mathrm{~nm}$. In the CW case, the probe power is about $11 \mathrm{dBm}$, and in the pulsed case about $0.3 \mathrm{dBm}$ average power $(\sim 12 \mathrm{dBm}$ peak power).
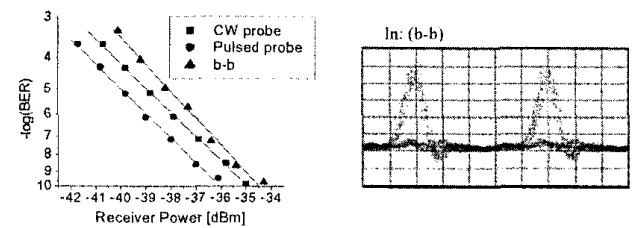

Out: CW probe
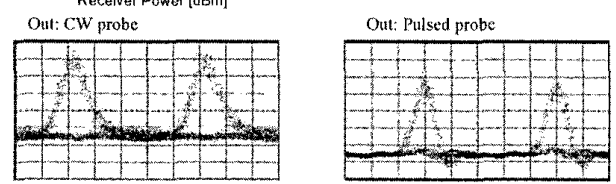

Figure 3: BER and eye diagrams for $10 \mathrm{~Gb} / \mathrm{s}$

wavelength conversion.

Figure 3 shows the BER curves and eye diagrams for the two cases, for a bias of $-2.2 \mathrm{~V}$. In both cases a negative penalty compared to the back-to-back (b-b) (directly from the transmitter to the receiver) is obtained. This is due to the nonlinearity of the transfer function, and clearly demonstrates the reshaping properties of wavelength conversion in an EAM [6]. In the CW case, the output eye clearly reveals a suppression of the " 0 "--level which is the fingerprint of the nonlinear transfer function. In the $\mathrm{CW}$ case the receiver sensitivity improvement is $0.5 \mathrm{~dB}$, whereas in the pulsed probe case, the improvement is 1.6 $\mathrm{dB}$. This better performance of the pulsed probe is primarily ascribed to the receiver's higher sensitivity to shorter pulses [8] (less average power is required to obtain the same SNR).

\section{All-optical Demultiplexing}

For demultiplexing, the GS-DFB acts as a $10 \mathrm{GHz}$ pump (at $1553 \mathrm{~nm}$ ) with only $8 \mathrm{pJ}$ pulse energy available, and the ML-FRL serves as pulse source for the 10,40 and $80 \mathrm{~Gb} / \mathrm{s}$ probe bit streams (at $1558 \mathrm{~nm}$ ) that are sent into the EAM. The probe has about $8 \mathrm{dBm}$ average power in all cases. Figure 4 shows the successful $40 / 10 \mathrm{~Gb} / \mathrm{s}$ demultiplexing results, in terms of BER curves and eye diagrams. The $10 / 10 \mathrm{~Gb} / \mathrm{s}$ demultiplexing has no power penalty compared to the back-to-back case, but a slight change in slope. Since the $10 / 10$ situation corresponds to the wavelength conversion situation, a $1.6 \mathrm{~dB}$ improvement is expected, but due to the less pump pulse energy available here the saturation of the absorption is not as effective. This is revealed by the slope change and the fact that there is no improvement in sensitivity. For the $40 / 10 \mathrm{~Gb} / \mathrm{s}$ demultiplexing there is a $2 \mathrm{~dB}$ penalty, where the major part is ascribed to the lack of pump power, but also to ISI stemming from the asymmetric switching window.

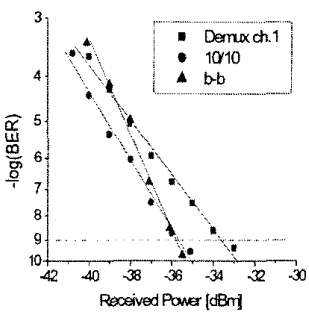

In

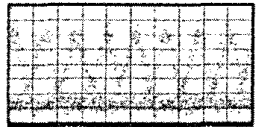

Ou

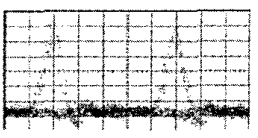

Figure 4: BER and eye diagrams for $40 / 10$ demultiplexing.

Figure 5 shows the first promising results for $80 / 10 \mathrm{~Gb} / \mathrm{s}$ demultiplexing. The EAM is set to $-3 \mathrm{~V}$ to obtain the narrowest switching window (intrinsic window $\sim 16 \mathrm{ps}$ ), and clear and open eyes are obtained for the demultiplexed channel.

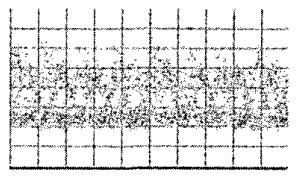

In $(80 \mathrm{~Gb} / \mathrm{s})$

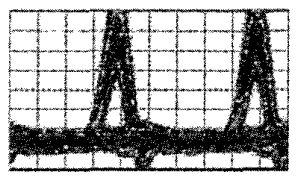

Out $(10 \mathrm{~Gb} / \mathrm{s})$
Figure 5: Eye diagrams for $80 / 10 \mathrm{~Gb} / \mathrm{s}$ demultiplexing.

The performance is limited though by the available pump power and the exponential tail of the switching window. A better performance is however expected at higher pump powers, and this preliminary result shows the great potential for the EAM as an all-optical demultiplexer.

\section{Conclusion}

Successful wavelength conversion at $10 \mathrm{~Gb} / \mathrm{s}$ is demonstrated with a negative penalty of $1.6 \mathrm{~dB}$. Successful all-optical demultiplexing of a $40 \mathrm{~Gb} / \mathrm{s}$ data signal down to $10 \mathrm{~Gb} / \mathrm{s}$ is demonstrated error-free, and with a $2 \mathrm{~dB}$ penalty mostly ascribed to the limited pump power. An $80 \mathrm{~Gb} / \mathrm{s}$ data signal is all-optically demultiplexed down to $10 \mathrm{~Gb} / \mathrm{s}$ yielding clear and open eyes.

\section{references}

/1/ B. Mikelsen et al. ECOC 2000, paper 6.1.1., 2000

/2/ T. Otani et al. OFC'2000, ThP3-1, pp.226-228, 2000

13/ K. Shimomura et al. ECOC 2000, paper 9.4.5, 2000

14/ K. Nishimura et al. OFC'2001, WK5-1, 2001

15/ H. Tanaka et al. OFC'2001, ME4-1, 2001

16/ S. Hojfeldt et al. J. Lightwave Technol., vol. 18, no. 8 , pp. $1121-1127,2000$

/7/ S. Diez et al. Optics Communications, Vol. 189, Issue $4-6$, pp. $241-249,2001$

18/ S.D. Personick, Bell Syst. Tech. J., Vol. 52, no. 843, 1973 